\title{
Establishment of an Adult T-Cell Leukemia Cell Line (HU-ATTAK) Dependent for Proliferation on Human Umbilical Cord Vein Endothelial Cells
}

\author{
Yoshitoyo Kagami $^{*}, 1,5$, Karnan Sivasundaram ${ }^{3}$, Aya nakagawa ${ }^{3}$, Kazuiku Oshiro ${ }^{4}$, Harumi Kato ${ }^{3}$, \\ Koichi Koike $^{2}$, Yasuo Morishima ${ }^{1}$ and Masao Seto ${ }^{*}, 3,6$
}

${ }^{I}$ Department of Hematology and Cell Therapy, ${ }^{2}$ Department of Clinical Laboratories, Aichi Cancer Center Hospital, ${ }^{3}$ Division of Molecular Medicine, Aichi Cancer Center Research Institute, ${ }^{4}$ Department of Hematology, Okinawa Prefectural Nanbu Medical Center \& Children's Medical Center, ${ }^{5}$ Department of Hematology, Toyota Kosei Hospital, ${ }^{6}$ Department of Cancer Genetics, Nagoya University Graduate School of Medicine, Japan

\begin{abstract}
A novel cell line, HU-ATTAK, was established from the peripheral blood of a patient with adult T-cell leukemia by means of co-culture with human umbilical cord vein endothelial cells (HUVEC) in the presence of interleukin-2 and damnacanthal. Immunophenotypic and cytogenetic analyses showed that HU-ATTAK is originally derived from leukemic cells and maintains the typical features of adult T-cell leukemia-lymphoma (ATLL). The growth of HU-ATTAK depends on IL-2 and HUVEC. When IL-2 was removed from the culture, HU-ATTAK stopped growing and eventually died through apoptosis. On the other hand, when HUVEC was removed from the culture, HU-ATTAK ceased proliferation but survived for a period of over two weeks. A culture experiment using micropore membranes showed that attachment of HU-ATTAK to HUVEC is necessary for proliferation. Stimulation of the co-stimulatory molecule OX40 ligand, which is expressed on HUVEC, is also involved in HU-ATTAK growth because the anti-OX40 ligand antibody completely inhibited the growth. These findings suggest the importance of the microenvironment for the survival and proliferation of some cases of ATLL. The HU-ATTAK cell line may thus be useful for studying the growth mechanism of ATLL and might yield new insights into the pathogenesis of ATLL.
\end{abstract}

Keywords: Adult T-cell leukemia/lymphoma, Human umbilical cord vein endothelial cells, OX40, cell line.

\section{INTRODUCTION}

Human T-cell leukemia virus type I (HTLV-I) [1] has been established as the causative agent of adult T-cell leukemia/lymphoma (ATLL) [2], but the mechanisms of tumorigenesis other than HTLV-I infection have largely remained speculative [3]. Okamoto et al. reported that five independent steps are necessary for acquisition of the final ATLL phenotype as an invasive neoplasm [4]. To clarify the abnormality of genetic or epigenetic changes, molecular analyses of fresh leukemia, lymphoma, or tumor cells have been conducted. These studies include cytogenetic analysis [5] and chromosome or array comparative genomic hybridization ( $\mathrm{CGH})[6,7]$, as well as investigation of RNA expression [8] or genomic instability $[9,10]$. However, it has been difficult to determine how such changes can contribute to tumorigenesis in ATLL. An in vitro culture system of ATLL may conserve such genetic changes involved in tumor development and thus yield some clues concerning the growth mechanism of ATLL. It is known that attempting to

*Address correspondence to these authors at the (YK) Department of Hematology, Toyota Kosei Hospital, 500-1, Ibohara, Josui-cho, Toyota, 470-0396, Japan; Tel: (+81) - 565-43-5000; Fax: (+81) - 565-43-5100; Email: y-kagami@toyota.jaaikosei.or.jp and (MA) Division of Molecular Medicine, Aichi Cancer Center Research Institute, 1-1 Kanokoden, Chikusa-ku, Nagoya 464-8681, Japan; Tel: (+81)-52-762-6111; Fax: (+81)52-763-5233; E-mail: mseto@aichi-cc.jp grow tumor cells of ATLL patients is very difficult, and only a few cell lines have been established [11-16]. Tumor cells of ATLL patients grow very vigorously in vivo, but differences between in vivo and in vitro proliferative features of ATLL have remained unclarified. We therefore examined the possibility of the stimulation of tumor cell growth by environmental factors which may work in vivo. We found that one approach for this purpose is the use of other kinds of cells as feeder cells. We previously reported that a human skin cancer cell line (HSC-I) supported growth of leukemic cells in some ATLL patients in the presence of IL-2, which then became HSC-I-dependent cell lines [14]. These cell lines would grow even though direct contact between the ATLL cell line and feeder cells was inhibited by a micropore membrane. However, the fact that some other ATLL patient cells would not grow under such conditions suggested the existence of other kinds of feeder cells. In the study presented here, we tried to establish ATLL cell lines using the human umbilical cord vein endothelial cell (HUVEC) as feeder cells, which expresses various adhesion molecules on its cell surface and exhibits the exocrine secretion of various cytokines. We succeeded in establishing a HUVECdependent cell line from among ten samples derived from peripheral blood or lymph node cells of ATLL cases. Analysis of factors derived from HUVEC indicated that the OX40 ligand was one of the growth factors of ATLL. 


\section{PATIENT AND METHODS}

\section{The Patient's Clinical Profile}

The patient was a 61-year-old Japanese male who was admitted because of poor performance status. He had systemic lymphadenopathy, hepatosplenomegaly and generalized erythematous skin. Laboratory data indicated hypercalcemia, renal failure and positivity of anti-HTLV-I antibody. The peripheral blood white cell count was elevated and contained $61 \%$ of flower-like cells whose immunological phenotype was $\mathrm{CD} 2(+), \mathrm{CD} 3(+), \mathrm{CD} 4(+)$, CD8(+), CD25(+), CD7(-) and CD19(-). From these clinical data, he was diagnosed with an acute type of ATLL. He received various combinations of chemotherapies, but had no remission and died. The peripheral mononuclear cells were frozen and preserved for the further analyses and the establishment of HUATAK.

\section{Cell Culture}

HUVEC was purchased from Lonza Walkersville, Inc. (Walkersville, MD, USA) and was maintained in EGM-2 medium with a Bullet Kit (CC-3162), which contains a growth supplement kit with hydrocortisone, hFGF- $\beta$, VEGF, R3 IGF-1, ascorbic acid, heparin, FBS, hEGF and GA-1000 (Lonza Walkersville, Inc.).

ATLL cells were co-cultivated with HUVEC using Iscove's modified Dulbecco's medium (IMDM) containing $20 \%$ human plasma, $10 \mathrm{ng} / \mathrm{ml}$ of IL-2 (PeproTech), and 20 nM damnacanthal (Calbiochem, Merck, Tokyo, Japan).

The established cell line, HU-ATTAK will be deposited to Riken Bioresource Center for academic use. (http://www.brc.riken.go.jp/lab/cell/english/).

\section{Flow Cytometry}

Surface immunophenotyping of the lymphoma, HUATTAK and HUVEC was performed using the following panel of lymphoid-associated monoclonal antibodies: HLADR (CR3/43), CD4 (RPA-T4), (DAKO Denmark), CD2 (RPA-2.10), CD3 (UCHT1), CD5 (L17F12), CD8 (SK1), CD10 (WM15), CD13 (WM15), CD14 (M5E2), CD19 (SJ25C1), CD20 (L27), CD25(M-A251), CD33 (P67.6), CD45 (2D1), CD56 (NKH-1), CD57 (NK-1), TCR $\alpha \beta($ WT31), TCR $\gamma \delta(11 \mathrm{~F} 2),($ BD Pharmingen, Japan BD, Tokyo, Japan), CD1a (BL6), CD7 (8H8.1), (Beckman Coulter, Inc. CA, USA), CD134(W4-3) and CD252(TAG34) (Medical \& Biological Laboratories, Nagoya, Japan). Multiparameter analysis of gated cell populations during cell suspension studies was used to yield more definitive immunophenotypic information (CELLQuest software, Becton-Dickinson, CA, USA).

\section{Cytogenetics}

Chromosomal analysis of the original leukemic cells and HU-ATTAK was performed at the Special Reference Laboratory (Tokyo, Japan). The analysis of HU-ATTAK was performed with conventional methods and karyotyped according to ISCN.

\section{DNA Extraction and Southern Blot Analysis}

For the extraction of high molecular weight DNA, the original bone marrow tumor and HU-ATTAK cells were treated with proteinase $\mathrm{K}$ and extracted with phenol and chloroform as described elsewhere [17]. Data of Southern blot analysis for the HTLV-I integration site were acquired from the Special Reference Laboratory.

\section{Array CGH}

DNA labelling, array fabrication, hybridization, normalization and analysis were performed as described previously [18]. The array CGH glasses used in the present study were ACC Version 5.0 [19]. The array consisted of 2304 BAC/PAC clones spotted in duplicate. These clones were from libraries RP11 and RP13 for BAC clones, and RP1, RP3, RP4 and RP5 for PAC clones. These clones were obtained from the BAC/PAC Resource Centre at the Children's Hospital, Oakland Research Institute, Oakland, CA, USA (http://bacpac.chori.org/). The BAC/PAC clones were aligned with each chromosome on the basis of data from Ensembl Genome Data Resources (release 40; http://www.ensembl.org/) or the National Centre for Biotechnology Information (Build 36; http://www. ncbi.nlm.nih.gov/ ). The locations of all the clones used for array $\mathrm{CGH}$ were confirmed by fluorescent in situ hybridization (FISH). Clones that showed unreliable data in 17 unrelated normal individuals were excluded from the data analysis. Clones of the sex chromosomes were also excluded. A total of 2125 clones (covering $2867 \mathrm{Mb}, 1.34-$ $\mathrm{Mb}$ resolution) were further analyzed.

Thresholds for copy number gain and loss were determined so that the estimated false discovery rate (FDR) was approximately 0.05 . The thresholds for gain and loss were +0.186868 and -0.144762 , respectively. We defined the region of gains and losses as: (a) three contiguous clones showing gain $(\log 2$ ratio +0.19 to +1.0$)$ or $\operatorname{loss}(\log 2$ ratio -1.0 to -0.15 ); or (b) clones, if not contiguous, showing high copy number gain $(\log 2$ ratio $>+1.0)$ or homozygous loss $(\log 2$ ratio $<-1.0)$.

\section{IL-2 Dependency of HU-ATTAK}

HUVEC were seeded in a 12-well cluster dish (Costar, Cambridge, MA, USA) on day -1 . On day 0 , after removal of the medium, $2 \mathrm{ml}$ of a HU-ATTAK cell suspension at a concentration of $5 \times 10^{4} / \mathrm{ml}$ was plated onto each well. Every 3 days, floating viable cells after pipetting were concentrated to $1 \mathrm{ml}$ and the number of viable cells was counted. Then $10^{5}$ HU-ATTAK cells were resuspended in 2 $\mathrm{ml}$ of fresh medium and seeded into new wells at a concentration of $5 \times 10^{4} / \mathrm{ml}$. For the IL-2-dependent growth assay, $10^{5}$ HU-ATTAK cells were cultured in a 12-well cluster in the presence or absence of $10 \mathrm{ng} / \mathrm{ml} \mathrm{IL-2.} \mathrm{The}$ viable cells were counted after three days.

\section{Dose Dependency of IL-2}

Dose dependency of IL-2 was examined as follows: $5 \mathrm{X}$ $10^{3}$ HU-ATTAK cells in the presence of HUVEC were cultured in $2 \mathrm{ml}$ of culture medium containing IL-2 in a 12well cluster dish. The IL-2 was serially diluted from 270 $\mathrm{ng} / \mathrm{ml}$ by one-thirds. After three days, $100 \mu \mathrm{l}$ of cell suspension from each well was transferred to a 96-well cluster dish. The number of viable cells was measured using a colorimetric assay (CellTiter 96TM; Aqueous NonRadioactive Cell Proliferation Assay Kit, Promega, Madison, 
WI, USA). The mean values of the absorbance at $490 \mathrm{~nm}$ in the quadruplicate wells were plotted as a growth curve.

\section{Detection of Apoptotic Cells}

$10^{5}$ HU-ATTAK cells were cultured on HUVEC with or without IL-2 for 2 days. These cells were washed and stained with FITC-labeled Annexin V (AN) and propidium iodide (PI) (Trevigen Inc., Gaithersburg, MD, USA). Early apoptotic cells which express phosphatidylserine on the outer cell membranes bind AN, and dead cells with a compromised cell membrane allow PI to bind to the cellular DNA. Using flow cytometric analysis, the degrees of apoptosis were measured with two populations of $\mathrm{AN}+/ \mathrm{PI}-$ (early apoptotic cells) and $\mathrm{AN}+\mathrm{PI}+$ (late apoptotic cells and necrotic cells).

\section{Transwell Culture Between HUVEC and HU-ATTAK}

A Transwell culture was established using a $0.4-\mu \mathrm{m}$ pored bottom cup (Transwell ${ }^{\circledR}$ Costar, Cambridge, MA, USA). On day -1, HUVEC were seeded into a 6-well cluster dish (Costar). On day $0,1.5 \mathrm{ml}$ of the culture medium was replenished, the pored bottom cups were settled, and then $10^{5}$ HU-ATTAK cell suspensions were inoculated. The number of viable cells was counted on days 3,5 and 7 .

\section{Growth Inhibition by Anti-OX40 or Anti-OX40 Ligand Antibody}

$10^{3} \mathrm{HUVEC} /$ well were cultured in a 96-well cluster dish (Costar) on day -1 . On day 0 , after removal of the medium, $100 \mu 1$ of HU-ATTAK suspension at a concentration of $5 \mathrm{X}$ $10^{4} / \mathrm{ml}$ was plated onto each well which contained various concentrations of monoclonal anti-OX40 or anti-OX40 ligand antibody in quadruplicates. Viable cell numbers of each cell suspension were counted every three days after pipetting. The cell density was maintained at $5 \times 10^{4} / \mathrm{ml}$, and 5 X $10^{3}$ HU-ATTAK cells were seeded into a new well of a 96-well cluster dish containing precultured HUVEC. If the cell density was less than $5 \times 10^{4} / \mathrm{ml}$, the whole cell suspension was centrifuged and the medium was changed to a new medium, then seeded into a new well.

\section{RESULTS}

\section{Establishment of HU-ATTAK}

The peripheral mononuclear cells frozen prior to the start of chemotherapy, were thawed and cultured in IDMEM with $20 \%$ human plasma and $10 \mathrm{ng} / \mathrm{ml}$ of human IL-2 in the presence or absence of HUVEC. However, the cells did not grow for long under either condition. During the search for agents to stimulate the growth of T-cell lymphoma in vitro, we found that the addition of $20 \mathrm{nM}$ damnacanthal to the medium stimulated the growth of leukemic cells for some ATLL cases in the presence of IL-2 (Fig. 1A). We therefore added $20 \mathrm{nM}$ damnacanthal to the IDMEM culture together with $20 \%$ human plasma and $10 \mathrm{ng} / \mathrm{ml}$ IL-2 without HUVEC. However, this condition did not support growth and the tumor cells ceased to grow. When HUVEC was added to this condition on September 2007, mononuclear cells kept growing vigorously for more than 4 months. Interestingly, after 4 months, the growth rate was identical whether damnacanthal was present or absent, although tumor cell growth was strictly dependent on the presence of IL-2 and HUVEC (Fig. 1B). This cell line which continued to grow for 9 months from the start of culture was designated as HU-ATTAK.

(A)

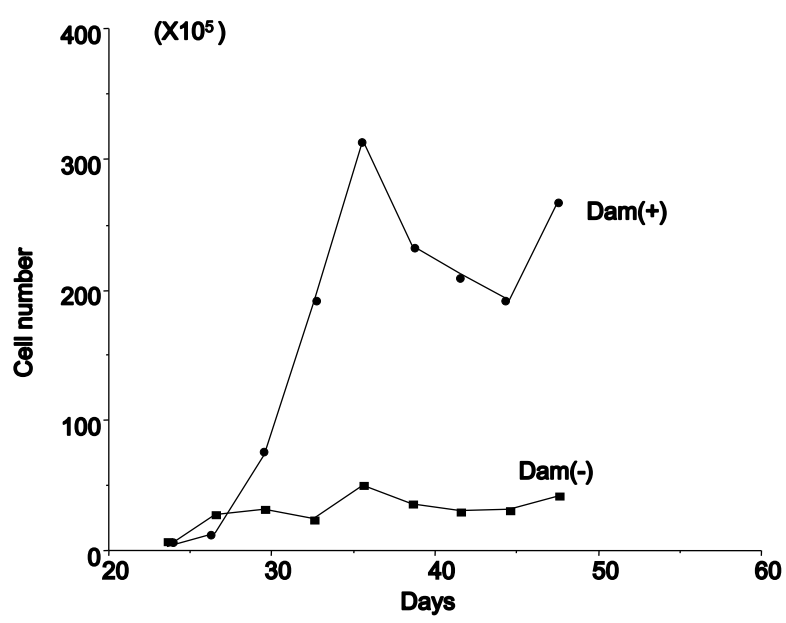

(B)

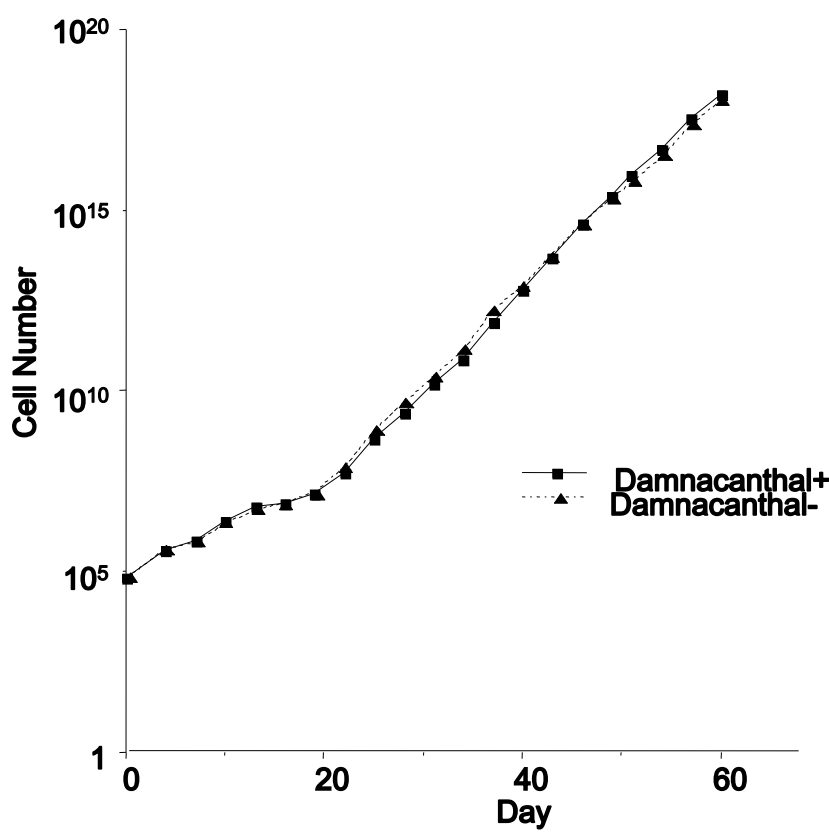

Fig. (1). (A) Representative growth curve of an ATLL case in the presence $(\bullet)$ or absence $(\boldsymbol{a})$ of $20 \mathrm{nM}$ damnacanthal without HUVEC. A cell line was not established in this case. (B) Representative growth curve of HU-ATTAK on HUVEC cells in the presence $(\boldsymbol{\square})$ or absence $(\boldsymbol{\Delta})$ of $20 \mathrm{nM}$ damnacanthal. A similar growth curve was observed in an independent experiment. Cell numbers are plotted using a log scale.

\section{Phenotypic and Genotypic Analyses}

The phenotypic analysis of the original leukemia and HU-ATTAK showed expression of CD3, CD4 and CD25, which are characteristic of ATLL. CD8 was positive in the original leukemic cells, but it became negative in the new cell line. The analyses of other phenotype of HU-ATTAK indicated that $\mathrm{CD} 1(-), \mathrm{CD} 2(+), \mathrm{CD} 5(+), \mathrm{CD} 7(-), \mathrm{CD} 10(-)$, CD13(+/-), CD19(-), CD56(-), CD57(+/-), HLA-DR(+), 
TCR- $\alpha \beta(-)$, and TCR- $\gamma \delta(-)$, which showed some aberrations from normal helper T-cells.

The proviral integration pattern of the original peripheral mononuclear cells and HU-ATTAK identified by means of Southern blot analysis showed that the clonal integration pattern of HTLV-I and the two flanking sequence bands were identical. However, the bands of the internal sequence of the gag-env gene were partially deleted in HU-ATTAK, which suggested that microdeletion occurred during establishment of the HU-ATTAK cell line (Fig. 2A).

Chromosomal analysis showed that the karyotype of the original leukemic cells was $\operatorname{idic}(18)(\mathrm{p} 11.2), \mathrm{i}(19)(\mathrm{p} 10)$ and

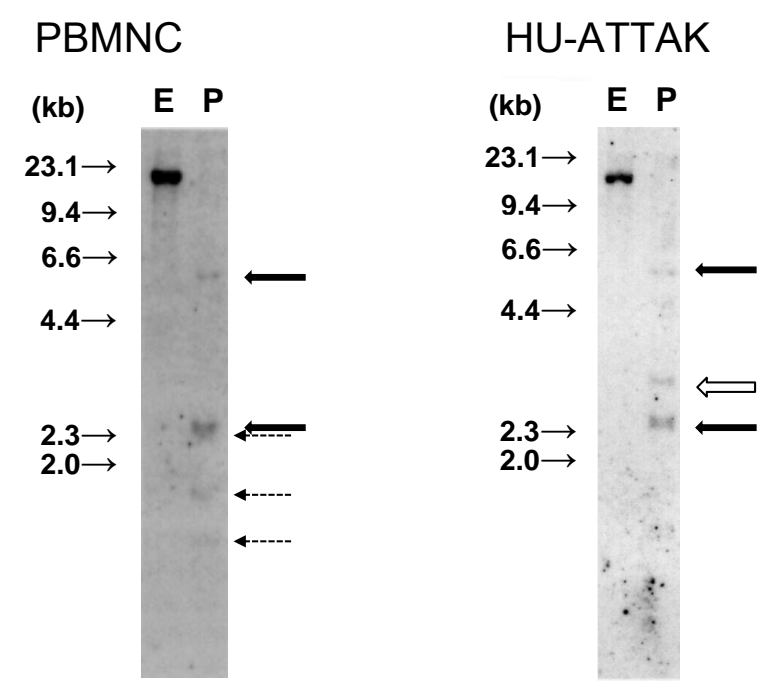

(B)

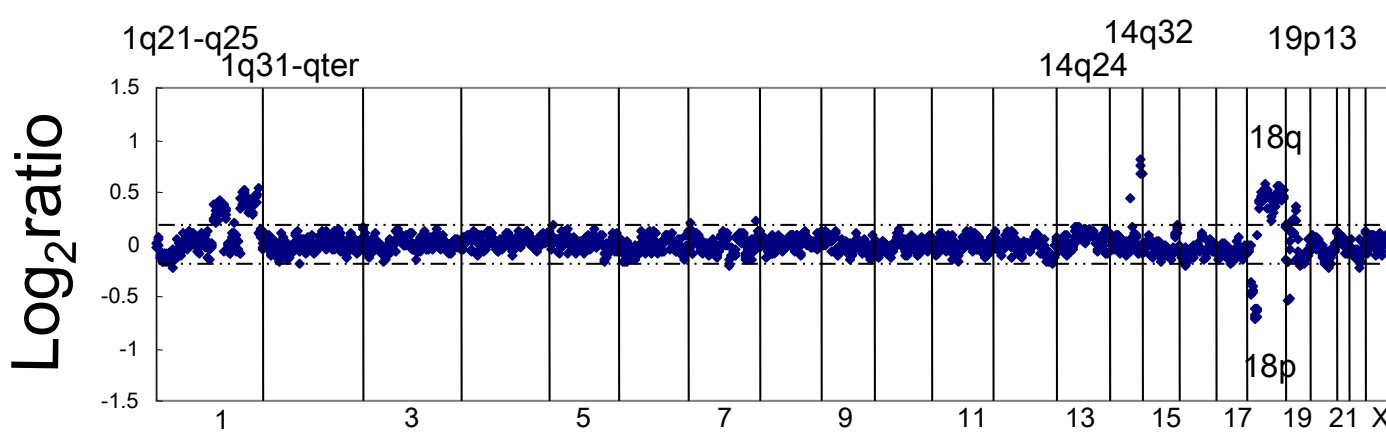

\section{PBL}

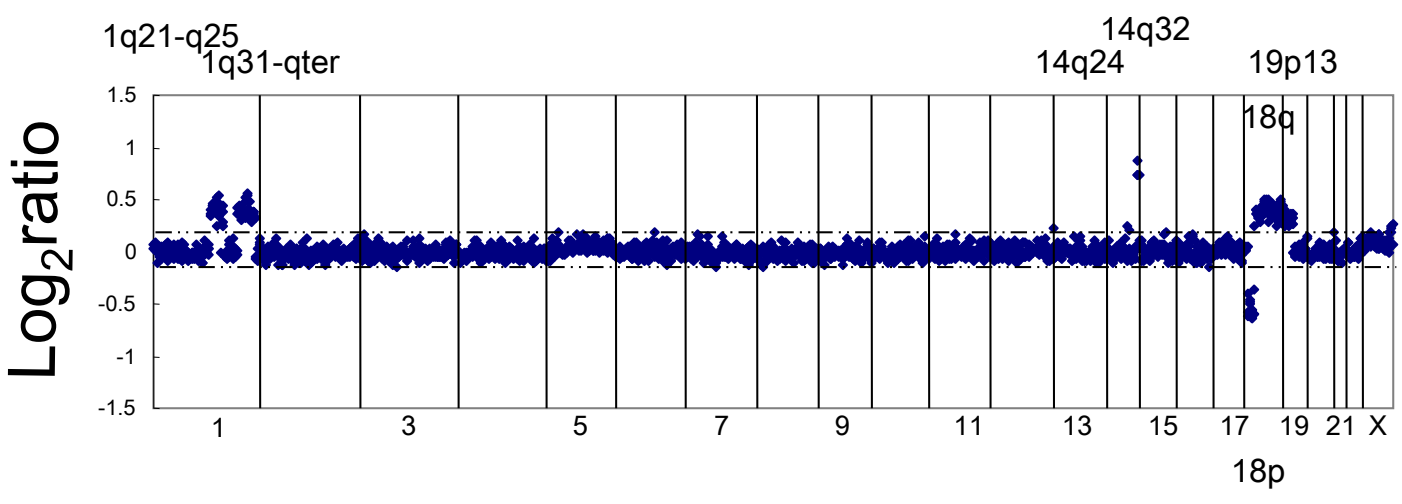

$\mathrm{CL}$

Fig. (2). (A) Southern blot analysis of HTLV-I integration pattern for mononuclear cells and HU-ATTAK. Left panel shows patient PBMNC and the right panel shows the HU-ATTAK cell line derived from the same patient. E, EcoRI digestion and P, Pst 1 . The bands of the flanking sequence (thick arrows) are identical to each other. The three bands of internal sequences of HTLV-I (dotted arrows) were deleted, while a new band (open arrow) was detected in HU-ATTAK. (B) CGH analysis of original PBMNC and HU-ATTAK. The loci of amplification and deletion are shown. 
+mar1, which was maintained in HU-ATTAK. Array CGH analysis was used for the critical analysis of constitutive DNA abnormalities. The major findings detected in the original leukemic cells were regions of gain in 1q21-25, $1 \mathrm{q} 32-44,14 \mathrm{q} 32.2,18 \mathrm{q} 11-23$ and $19 \mathrm{p} 13.11$, and a region of loss in 18p11 (Fig. 2B). The majority of these aberrations were conserved in HU-ATTAK. The results of these analyses proved that HU-ATTAK was derived from the original leukemic cells.

\section{IL-2-Dependent Growth of HU-ATTAK Cells}

After establishment of the HU-ATTAK cell line on HUVEC in the presence of IL-2, we examined to what extent this cell line depended for its growth on each of the factors. First, IL-2 was removed from the culture and as a consequence HU-ATTAK cells stopped growing, and almost all the cells died within three days even in the presence of HUVEC cells (Fig. 3A). The cell death mechanism in the absence of IL-2 was examined with the Annexin V/PI staining method (Fig. 3B). The cultured cells were stained with FITC-labeled annexin V and propidium iodide (PI) and analyzed using a FACS scan 24,48 and 72 hours later. Annexin V positive apoptotic cells increased from 24 hours, which demonstrated the anti-apoptotic effect of IL-2.

The growth promotion by IL-2 was examined in the presence of serially diluted concentrations of IL-2, and dose dependence was observed for concentrations from $370 \mathrm{pg} / \mathrm{ml}$ to $30 \mathrm{ng} / \mathrm{ml}$. The growth rate was less than twice that obtained with the minimum concentration, indicating that the growth promotion activity of IL-2 was weak (Fig. 3C). These findings indicated that IL-2 had a potent anti-apoptotic effect and a weak growth promotion action.

\section{HUVEC-Dependent Growth}

Next, HUVEC cells were removed from the culture. Fig. (4) shows the growth curve of HU-ATTAK cells in the presence of IL-2 but without HUVEC. In the culture without HUVEC, the growth rate was similar to that of the control culture for three days, after which proliferation stopped and the cells survived for 2 weeks. These findings indicated that HUVEC promoted the proliferation of HU-ATTAK in the presence of IL-2.

\section{Direct Contact is Necessary for Growth of HU-ATTAK}

We examined whether direct contact with HUVEC cells is required for HU-ATTAK to grow. HU-ATTAK was cultured in an inner cup separated from HUVEC cells by a $0.4-\mu \mathrm{m}$ microporous membrane to prevent direct cell-to-cell contact. In the absence of direct contact, HU-ATTAK stopped growing a few days later and finally died. These findings suggested that the molecule(s) expressed on the surface of HUVEC could sustain HU-ATTAK growth (Fig. 5).

\section{Growth Promotion of HUVEC is Derived from the OX40 Ligand}

HUVEC expresses the OX40 ligand, which is a molecule that acts against ATLL cells by means of adhesion and antiapoptosis $[20,21]$. OX40 ligand expression was limited to HUVEC while OX40 expression was limited to HU-ATTAK (Fig. 6A). We examined the effect of the OX40 ligand on
(A)

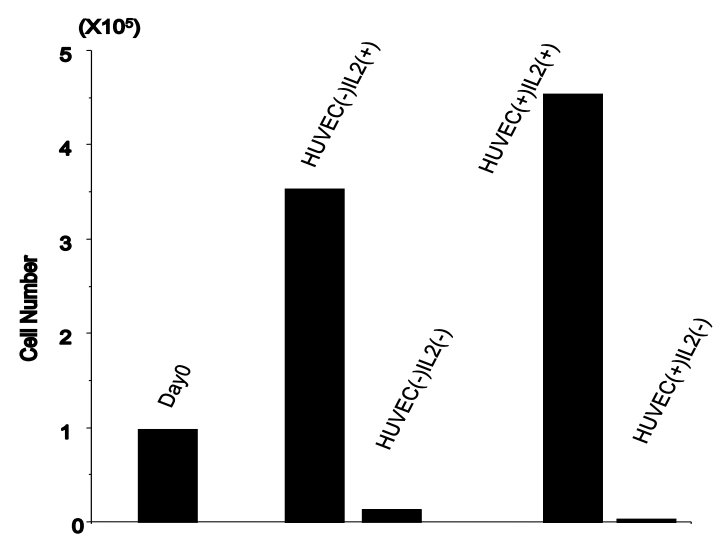

(B)

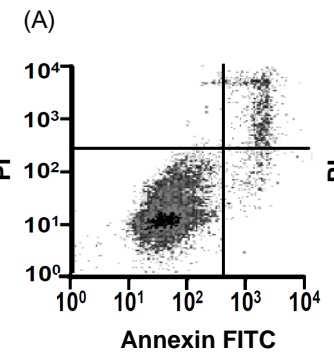

(B)

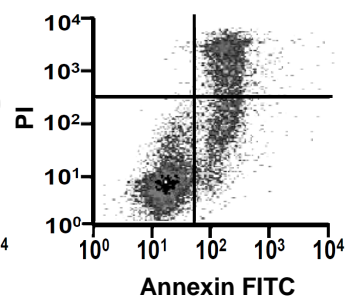

(C)

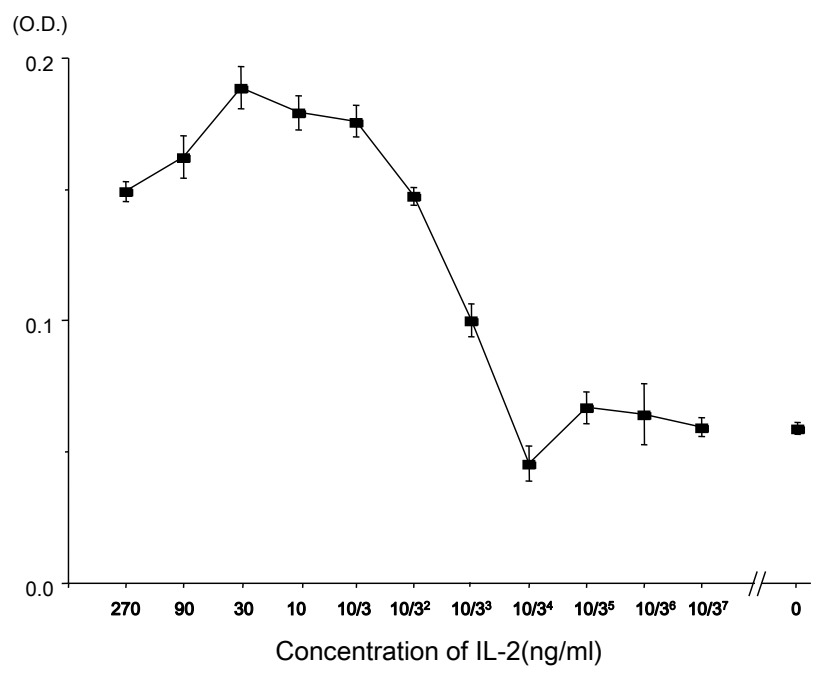

Fig. (3). Promotion and inhibition of HU-ATTAK cell growth by IL-2. (A) HU-ATTAK cell death without IL-2. HUVEC was cultured in a 12 -well cluster dish on day $-1.10^{5}$ cells of HUATTAK were cultured with or without HUVEC or IL-2. The numbers of viable cells were counted on day 3. This is a representative of two independent experiments. (B) Apoptotic cell death of HU-ATTAK in the absence of IL-2. Flow cytometric analysis of apoptosis after 48 hours from the deprivation of IL-2 is shown. The fluorescence intensities of AN (abscissa) and PI (vertical) are plotted. A representative of three experiments is shown. (C) Dose response curve of various concentrations of IL-2 in the presence of HUVEC. HUVECs were cultured in a 12-well cluster dish on day $-1.10^{5}$ cells of HU-ATTAK were cultured in 2 $\mathrm{ml}$ of medium containing serially diluted IL-2. The mean value of quadruplicate assays is shown. This is a representative of two independent experiments. 


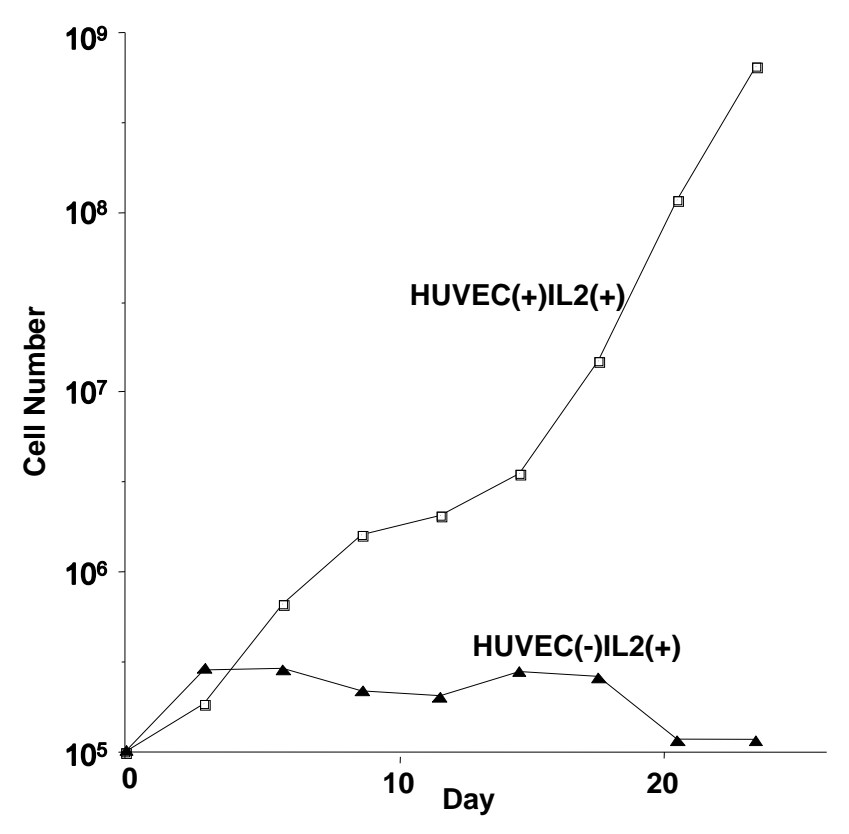

Fig. (4). Growth curve of HU-ATTAK cells in the presence or absence of HUVEC. $10^{5}$ cells of HU-ATTAK with IL-2 were cultured with or without HUVEC. The numbers of viable cells were counted every 3 days. This is a representative of two independent experiments. Cell numbers are plotted using a log scale.

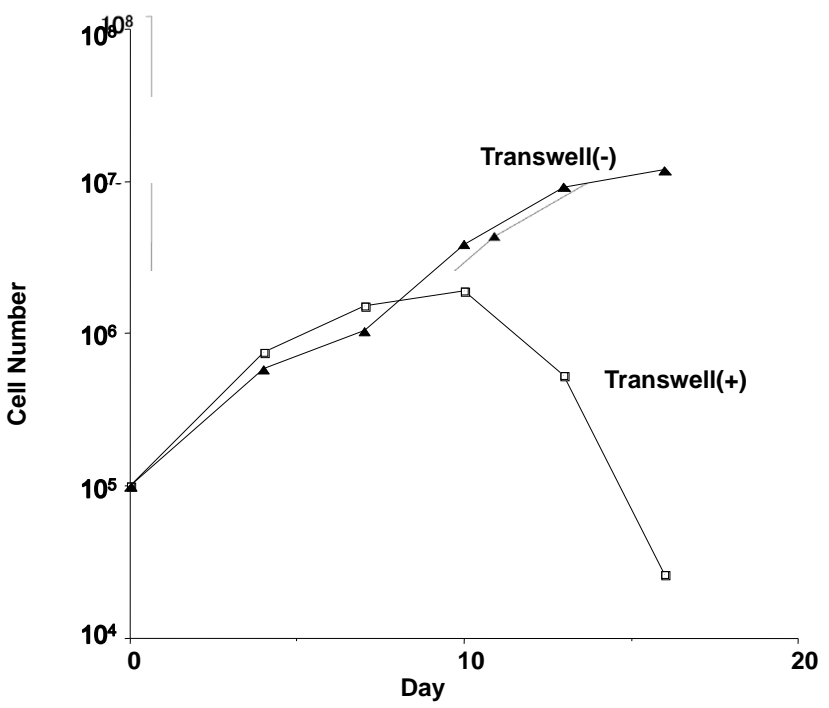

Fig. (5). Separation of HUVEC and HU-ATTAK prevents the growth of HU-ATTAK. HU-ATTAK and HUVEC were separated with a micropore membrane and cultured. As a control, HUATTAK cells were cultured with HUVEC without a membrane. The numbers of viable cells in the three wells were counted on days $4,7,10,13$ and 16. This is a representative of two independent experiments. Cell numbers are plotted using a log scale.

HU-ATTAK growth by adding an antibody to the culture system. In the presence of the anti-OX40 ligand antibody, the growth of HU-ATTAK was inhibited to the same level as that in the culture without HUVEC (Fig. 6B). On the other hand, the inhibitory effect was weak in the presence of the anti-OX40 antibody (Fig. 6C). These findings indicated that growth promotion by HUVEC is dependent on its expression of the OX40 ligand.

\section{DISCUSSION}

The mechanism of tumor cell growth in ATLL has been unclear, and analysis of ATLL-derived cell lines is therefore important. However, it has been difficult to establish cell lines from original tumor cells. Most ATL-derived cell lines have been established in the presence of IL-2 [16]. Although various cytokines can transiently stimulate the growth of normal T-cells, proliferation of ATLL cells by IL-2 is limited in spite of high expression of the IL-2 receptor $\alpha$ chain [22]. Establishment of an ATLL-derived cell line is therefore relatively rare. This difficulty may be explained by the presence of regulatory mechanisms other than IL-2 and/or factors supplementary to IL-2.

We hypothesized that tumor cell growth might be aided by environmental factors, including cytokines. Since one of the candidate factors is a cell-to-cell interaction between the cells in the microenvironment, we used HUVEC as feeder cells which might then function as alternatives for microenvironmental factors. Although HUVEC alone had no effect on the growth of ATLL, in combination with damnacanthal and IL-2 it could maintain the growth of ATLL cells for one in ten ATLL cases.

We have tried the kinase inhibitors genistein and damnacanthal, expecting that such inhibitors might affect cell growth signaling. Interestingly, damnacanthal had a stimulatory effect for this culture system. Damnacanthal is a tyrosine kinase inhibitor specific to $\mathrm{p} 56^{\mathrm{lck}}[23]$ and has a biological inhibitory effect on apoptosis induced by $14 \mathrm{kDa}$ human immunodeficiency virus-1 viral protein $\mathrm{R}$ (Vpr) [24]. $\mathrm{p} 56^{\mathrm{lck}}$ is the signaling protein activated through the T-cell receptor and is phosphorylated by the activated IL-2 receptor $\beta$ chain $[25,26]$. Although the detailed downstream signal transduction of $\mathrm{p} 56^{\text {lck }}$ through IL-2 is unknown, dephosphorylation of $\mathrm{p} 56^{\text {lck }}$ by damnacanthal may play a role in the establishment of HU-ATTAK in the early stage of the primary culture. The growth promotion effect of damnacanthal was not limited to ATLL cells because we could use damnacanthal to establish another IL-2-dependent cell line derived from T-cell lymphoma (manuscript in preparation).

In the study presented here, the growth promotion of HUVEC was proved to be mediated by the OX40-OX 40 ligand system. ATLL cells frequently express OX40 molecules, which help ATLL cells attach to endothelial cells [20]. OX40 is a member of the TNF receptor family and its stimulation inhibits apoptosis of ATLL cells by FAS [21] or transfers the signals for the activation of NF- $\mathrm{KB}$ [27]. The activation of NF- $\mathrm{\kappa B}$ is known to consistently persist in ATLL cells in vivo [28], especially by means of the NF- $\kappa B$ inducing kinase [29]. The activation of NF- $\kappa B$ through OX40 may thus be related to the growth promotion of HUATTAK, which can be used as model system for functional studies of ATLL cells.

Our analysis of the growth mechanism of HU-ATTAK established that both growth promotion and inhibition of apoptosis depended on environmental factors. Since these mechanisms have been identified only in this cell line, it is necessary to clarify whether tumor cells of patients can grow in a similar environment in vivo. Although it has been 
(A)

HU-ATTAK
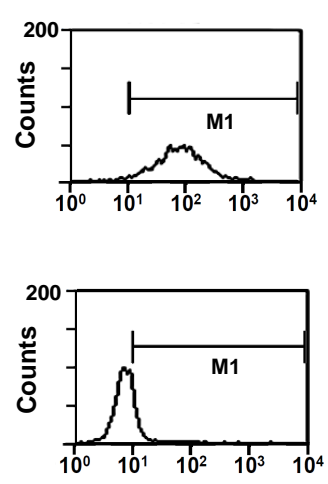
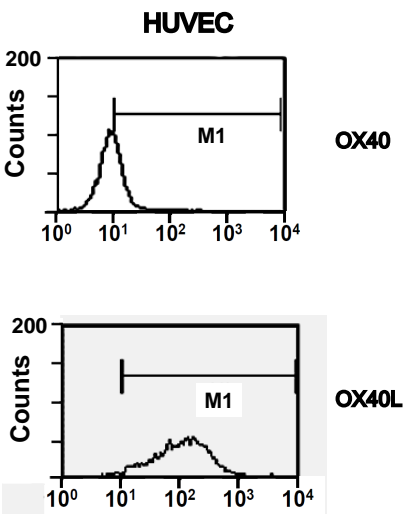

(B)

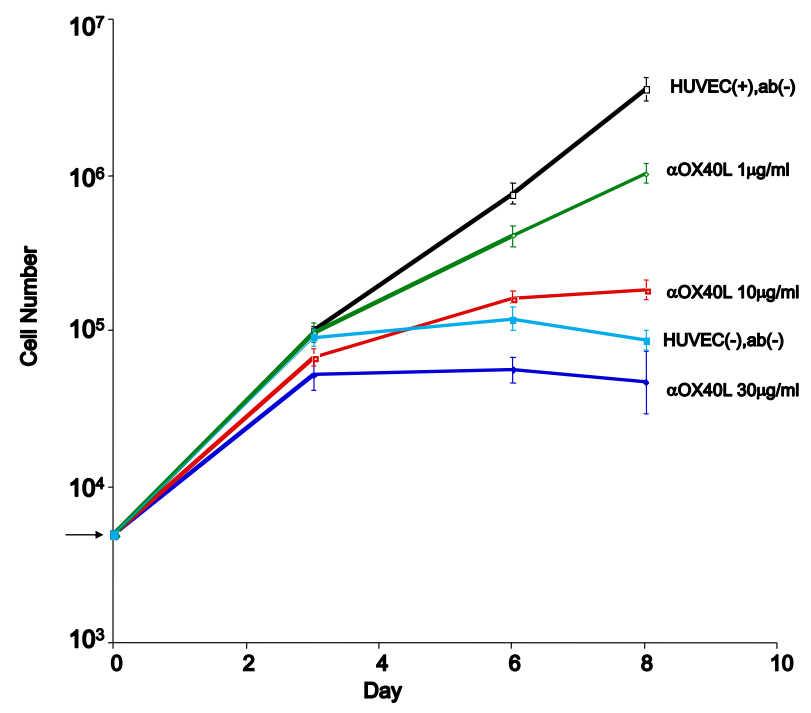

(C)

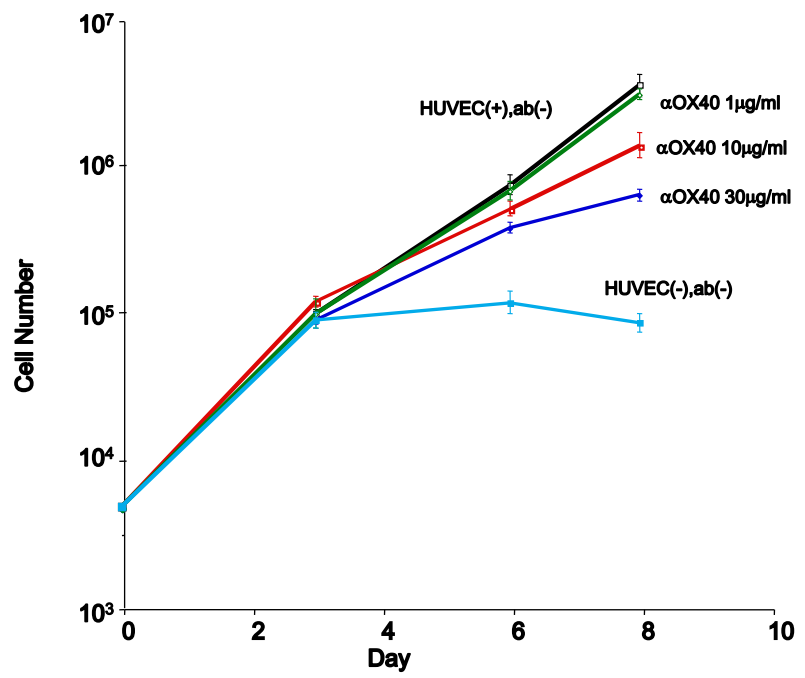

Fig. (6). Growth inhibition by anti-OX40 ligand and anti-OX40 antibody. (A) Expression of OX40 ligand or OX40 on HUVEC or HUATTAK as determined by flow cytometry. (B) Anti-OX40 ligand antibody completely inhibits the growth of HU-ATTAK. HU-ATTAK cells in quadruplicate culture were cultured in the presence of $0 \mu \mathrm{g} / \mathrm{ml}(\square), 1 \mu \mathrm{g} / \mathrm{ml}(\boldsymbol{\Delta}), 10 \mu \mathrm{g} / \mathrm{ml}(\bullet)$ and $30 \mu \mathrm{g} / \mathrm{ml}(\boldsymbol{\bullet})$ of OX40 ligand antibody. The negative control was the absence of HUVEC (०). Cells were counted on days 3, 6 and 8 . This is a representative of two independent experiments. Cell numbers are plotted using a log scale. (C) Anti-OX40 antibody partially inhibits the growth of HU-ATTAK. HU-ATTAK cells in quadruplicate culture were cultured in the presence of $0 \mu \mathrm{g} / \mathrm{ml}(\square), 1 \mu \mathrm{g} / \mathrm{ml}(\boldsymbol{\Delta}), 10 \mu \mathrm{g} / \mathrm{ml}(\bullet)$ and $30 \mu \mathrm{g} / \mathrm{ml}(\bullet)$ of OX40 antibody. The negative control was without HUVEC (०). Cells were counted on days 3, 6 and 8 . This is a representative of two independent experiments. Cell numbers are plotted using a log scale. 
established that HTLV-I is the original causative agent of ATLL, the pathophysiological and clinical courses of this disease differ significantly. If interaction with the environment causes oncogenesis in the later stage of ATLL, analysis of the growth mechanism of HU-ATTAK may provide insights into the molecular pathogenesis of ATLL, and thus might yield new therapeutic strategies.

\section{ACKNOWLEDGEMENTS}

The authors thank MT Hagino, MT Okada and MT Tanaka for their technical assistance.

This investigation was supported in part by a grant-in-aid from the Ministry of Health and Welfare, and a grant-in-aid from the Ministry of Education, Science and Culture of Japan.

\section{REFERENCES}

[1] Yoshida M, Miyoshi I, Hinuma Y. Isolation and characterization of retrovirus from cell lines of human adult T-cell leukemia and its implication in the disease. Proc Natl Acad Sci USA 1982; 79: 2031-5.

[2] Uchiyama T, Yodoi J, Sagawa K, Takatsuki K, Uchino H. Adult Tcell leukemia: clinical and hematologic features of 16 cases. Blood 1977; 50: 481-92.

[3] Yasunaga J, Matsuoka M. Human T-cell leukemia virus type I induces adult T-cell leukemia: from clinical aspects to molecular mechanisms. Cancer Control 2007; 14: 133-40.

[4] Okamoto T. Multi-stop carcinogenesis model for adult T-cell leukemia. Rinsho Ketsueki 1990; 31: 569-71.

[5] Kamada N, Sakurai M, Miyamoto K, et al. Chromosome abnormalities in adult T-cell leukemia/lymphoma: a karyotype review committee report. Cancer Res 1992; 52: 1481-93.

[6] Tsukasaki K, Krebs J, Nagai K, et al. Comparative genomic hybridization analysis in adult T-cell leukemia/lymphoma: correlation with clinical course. Blood 2001; 97: 3875-81.

[7] Oshiro A, Tagawa H, Ohshima K, et al. Identification of subtypespecific genomic alterations in aggressive adult T-cell leukemia/lymphoma. Blood 2006; 107: 4500-7.

[8] Kohno T, Moriuchi R, Katamine S, Yamada Y, Tomonaga M, Matsuyama T. Identification of genes associated with the progression of adult $\mathrm{T}$ cell leukemia (ATL). Jpn J Cancer Res 2000; 91: 1103-10.

[9] Hatta Y, Yamada Y, Tomonaga M, Miyoshi I, Said JW, Koeffler HP. Microsatellite instability in adult T-cell leukaemia. $\mathrm{Br} \mathrm{J}$ Haematol 1998; 101: 341-4.

[10] Hayami Y, Komatsu H, Iid a S, et al. Microsatellite instability as a potential marker for poor prognosis in adult $\mathrm{T}$ cell leukemia/lymphoma. Leuk Lymphoma 1999; 32: 345-9.

[11] Maeda M, Shimizu A, Ikuta K, et al. Origin of human Tlymphotrophic virus I-positive $\mathrm{T}$ cell lines in adult $\mathrm{T}$ cell leukemia. Analysis of T cell receptor gene rearrangement. J Exp Med 1985; 162: $2169-74$.

[12] Shirono K, Hattori T, Matsuoka M, Matsushita S, Asou N, Takatsuki K. Adult T cell leukemia cell lines that originated from primary leukemic clones also had a defect of expression of CD3-T cell receptor complex. Leukemia 1988; 2: 728-33.

[13] Naoe T, Akao Y, Yamada K, et al. Cytogenetic characterization of a T-cell line, ATN-1, derived from adult T-cell leukemia cells. Cancer Genet Cytogenet 1988; 34: 77-88.

[14] Kagami Y, Kinoshita T, Shimoyama M, Miwa M. A solublefactor(s) secreted by a human skin cancer cell line supports clonal growth of adult T-cell leukemia cells. Jpn J Cancer Res 1988; 79: 424-7.

[15] Yamada Y, Nagata Y, Kamihira S, et al. IL-2-dependent ATL cell lines with phenotypes differing from the original leukemia cells. Leuk Res 1991; 15: 619-25.

[16] Yamada Y, Fujita M, Suzuki H, et al. Established IL-2-dependent double-negative (CD4- CD8-) TCR alpha beta/CD3+ ATL cells: induction of CD4 expression. Br J Haematol 1994; 88: 234-41.

[17] Kagami Y, Jung J, Choi YS, et al. Establishment of a follicular lymphoma cell line (FLK-1) dependent on follicular dendritic celllike cell line HK. Leukemia 2001; 15: 148-56.

[18] Ota A, Tagawa $\mathrm{H}$, Karnan $\mathrm{S}$, et al. Identification and characterization of a novel gene, C13orf25, as a target for 13q31q32 amplification in malignant lymphoma. Cancer Res 2004; 64: 3087-95.

[19] Nakagawa M, Nakagawa-Oshiro A, Karnan S, et al. Array comparative genomic hybridization analysis of PTCL-U reveals a distinct subgroup with genetic alterations similar to lymphoma-type adult T-cell leukemia/lymphoma. Clin Cancer Res 2009; 15: 30-8.

[20] Imura A, Hori $\mathrm{T}$, Imada $\mathrm{K}$, et al. OX40 expressed on fresh leukemic cells from adult T-cell leukemia patients mediates cell adhesion to vascular endothelial cells: implication for the possible involvement of OX40 in leukemic cell infiltration. Blood 1997; 89: 2951-8.

[21] Kunitomi A, Hori T, Maeda M, Uchiyama T. OX40 signaling renders adult T-cell leukemia cells resistant to Fas-induced apoptosis. Int J Hematol 2002; 76: 260-6.

[22] Uchiyama T, Kamio M, Kodaka $T$, et al. Leukemic cells from some adult T-cell leukemia patients proliferate in response to interleukin-4. Blood 1988; 72: 1182-6

[23] Faltynek CR, Schroeder J, Mauvais P, et al. Damnacanthal is a highly potent, selective inhibitor of p56lck tyrosine kinase activity. Biochemistry 1995; 34: 12404-10.

[24] Kamata M, Wu RP, An DS, et al. Cell-based chemical genetic screen identifies damnacanthal as an inhibitor of HIV-1 Vpr induced cell death. Biochem Biophys Res Commun 2006; 348: 1101-6.

[25] Nelson BH, Willerford DM. Biology of the interleukin-2 receptor. Adv Immunol 1998; 70: 1-81.

[26] Palacios EH, Weiss A. Function of the Src-family kinases, Lck and Fyn, in T-cell development and activation. Oncogene 2004; 23: 7990-8000

[27] Watts TH. TNF/TNFR family members in costimulation of T cell responses. Annu Rev Immunol 2005; 23: 23-68.

[28] Hironaka N, Mochida K, Mori N, Maeda M, Yamamoto N, Yamaoka S. Tax-independent constitutive IkappaB kinase activation in adult T-cell leukemia cells. Neoplasia 2004; 6: 26678 .

[29] Saitoh Y, Yamamoto N, Dewan MZ, et al. Overexpressed NF$\{\mathrm{kappa}\} \mathrm{B}$ inducing kinase contributes to the tumorigenesis of adult T-cell leukemia and Hodgkin Reed-Sternberg cells. Blood 2008; 111: 5118-29.

(C) Kagami et al.; Licensee Bentham Open.

This is an open access article licensed under the terms of the Creative Commons Attribution Non-Commercial License (http: //creativecommons.org/licenses/by$\mathrm{nc} / 3.0 /$ ) which permits unrestricted, non-commercial use, distribution and reproduction in any medium, provided the work is properly cited. 